\title{
High-level secretory expression, purification, and characterization of an anti-human Her II monoclonal antibody, trastuzumab, in the methylotrophic yeast Pichia pastoris
}

\author{
Tatsuro Shibui $^{* *}$, Keisuke Bando ${ }^{2}$, Satoru Misawa ${ }^{2,3}$ \\ ${ }^{1}$ Food Biotechnology Laboratory, School of Food Sciences, Nippon Veterinary and Life Science University, 2-17-5 Sakai, Musashi- \\ no-Shi, Tokyo, Japan \\ ${ }^{2}$ API Corporation, Bio and Chemical Process Discovery Laboratory, 1000 Kamoshida-Cho, Aoba-Ku, Yokohama, Japan \\ ${ }^{3}$ Mitsubishi Chemical Group Science and Technology Research Center, 1000 Kamoshida-Cho, Aoba-Ku, Yokohama, Japan \\ Email: tshibui@nvlu.ac.jp
}

Received 28 March 2013; revised 3 May 2013; accepted 15 May 2013

Copyright (C) 2013 Tatsuro Shibui et al. This is an open access article distributed under the Creative Commons Attribution License, which permits unrestricted use, distribution, and reproduction in any medium, provided the original work is properly cited.

\begin{abstract}
DNA fragments encoding the light chain and heavy chain genes of an anti-human HER II antibody, trastuzumab, fused with an egg-lysozyme signal peptide were synthesized based on the codon bias of the methylotrophic yeast Pichia pastoris. These fragments were inserted into a site between the AOX 1-promoter and -terminator in PPICZ A to be expressed by $P$. pastoris. The expression vector was linearized, and introduced into $P$. pastoris GS115 by electroporation. After the checking of several transformants with PCR to ensure a precise insertion, one was selected and cultured to examine antibody production. The level of production reached $10 \mathrm{mg} / \mathrm{L}$ in a flask with medium containing $1 \%$ methanol. The heavy chain and light chain of the product were assembled to form a hetero tetramer, as detected by dodecyl sulfate polyacrylamide gel electrophoresis (SDS-PAGE). N-terminal amino acid sequencing revealed that the signal peptides of both chains were well processed. The mobility of the product in SDS-PAGE after treatment with Peptide $\mathrm{N}$-Glycosidase $\mathrm{F}$ indicated the heavy chain to be $\mathrm{N}$-glycosylated. Further analysis of the $\mathrm{N}$-glycans with a mass spectrometer revealed a mixture of $\mathrm{Man}_{9}$ GlcNAc $_{2}, \operatorname{Man}_{10}$-GlcNAc $_{2}$, Man $_{11^{-}}$GlcNAc $_{2}$ and Man $_{12}{ }^{-}$ GlcNAc $_{2}$, but no hyper-mannosylated glycans. ELISA, surface plasmon resonance, and flow cytometric studies showed the affinity curve and $K_{d}$ value for the antigen, HER II, and reactivity to a HER2-overexpressing breast cancer cell-line, SK-BR-3, to be almost the same as for the clinically used trastuzumab produced by $\mathrm{CHO}$.
\end{abstract}

Keywords: Pichia Pastoris; Antibody; Secretory Production; Glycocylation; Her II

\section{INTRODUCTION}

Recombinant monoclonal antibodies (mAbs) are useful for biological research, diagnostics and therapeutic purposes. In most cases, the host cells for production are mammalian cell lines, such as Chinese ovary cells [1] and NS0 [2]. All approved monoclonal antibodies at present are produced by mammalian cell lines [3]. Since mammalian cell cultures are far more complex and expensive than microbial cell cultures, expression systems with microorganisms have gained importance. However, bacterial systems, such as Esherichia coli, are often not able to modify the product as mammalian cells do.

With their capacity for post-translational modifications and potential to produce large quantities of rather complicated heterologous proteins, yeast production systems are seen as promising substitutes for mammalian cell systems [4,5]. Among several yeast systems, one using $P i$ chia pastoris is increasingly being applied to both research and the production of proteins for diagnostic and therapeutic purposes. Use of its AOX 1-promoter [6], which controls the expression of the enzyme alcohol oxidase, led to the development of methanol-inducible expression systems. The hyperglycosylation that tends to occur with Saccharomyces cerevisiae is much less a problem with P. pastoris [7], and the expressed proteins can either be kept inside the cells or be secreted into the culture medium. For secreted proteins, the purification process is expected to be simpler than that inside cells, 
since a reasonably high purity could be achieved in the supernatants. The amount of protein produced is usually in the range of $30 \%-80 \%$ of all the secreted proteins $[8,9]$. Since the ability to attain very high cell densities (150 - $400 \mathrm{~g}$ wet cell/L can be reached in defined media $[9,10])$ by fermentative growth using bioreactors allows for high volumetric productivity, $P$. pastoris has become a robust system for the production of recombinant proteins.

Trastuzumab, an antibody directed against the human Her II protein produced by $\mathrm{CHO}$, has been clinically used for the treatment and diagnosis of breast cancer [11]. However, the production costs are high, and alternative systems have been desired.

In this paper, we describe the construction of a $P$. pastoris strain capable of the extra-cellular expression of trastuzumab, its production in a flask culture, and results on the comparative characterization of the secretory product with a commercially available trastuzumab produced by $\mathrm{CHO}$.

\section{MATERIALS AND METHODS}

\subsection{Antibodies, Bacterial and Yeast Strains, and a Plasmid}

Herceptin (trastuzumab produced by $\mathrm{CHO}$ ) and Retuxin (rituximab produced by $\mathrm{CHO}$ ) were purchased from Roche (USA).

Other antibodies used in immunoassays were from R\&D Sciences (USA) and Life Span Biosciences (USA).

JM 109 competent cells used for plasmid construction were from Toyobo Biochemicals (Japan).

Picha pastoris GS115 and pPICZ A for expression of the target genes were from Life Technologies (USA).

\subsection{Genes for Trastuzumab Heavy $(\mathrm{H})$ and Light (L) Chains}

Genes for trastuzumab heavy $(\mathrm{H})$ chain and light $(\mathrm{L})$ chain amino acid sequences [11] as listed below, where codons were optimized for expression in $P$. pastoris, were designed, and synthesized by GenScript (USA).

Trastuzumab H chain 451 amino acids;

EVQLVESGGGLVQPGGSLRLSCAASGFNIKDTYI HWVRQAPGKGLEWVARIYPTNGYTRYADSVKGR FTISADTSKNTAYLQMNSLRAEDTAVYYCSRWGG DGFYAMDYWGQGTLVTVSSASTKGPSVFPLAPSS KSTSGGTAALGCLVKDYFPEPVTVSWNSGALTSG VHTFPAVLQSSGLYSLSSVVTVPSSSLGTQTYICNV NHKPSNTKVDKKVEPPKSCDKTHTCPPCPAPELLG GPSVFLFPPKPKDTLMISRTPEVTCVVVDVSHEDPE VKFNWYVDGVEVHNAKTKPREEQYNSTYRVVSV LTVLHQDWLNGKEYKCKVSNKALPAPIEKTISKA KGQPREPQVYTLPPSRDELTKNQVSLTCLVKGFYP SDIAVEWESNGQPENNYKTTPPVLDSDGSFFLYSK

\section{LTVDKSRWQQGNVFSCSVMHEALHNHYTQKSLS} LSPGK

Trastuzumab L chain 214 amino acids;

DIQMTQSPSSLSASVGDRVTITCRASQDVNTAV AWYQQKPGKAPKLLIYSASFLYSGVPSRFSGSRSG TDFTLTISSLQPEDFATYYCQQHYTTPPTFGQGTKV EIKRTVAAPSVFIFPPSDEQLKSGTASVVCLLNNFY PREAKVQWKVDNALQSGNSQESVTEQDSKDSTYS LSSTLTLSKADYEKHKVYACEVTHQGLSSPVTKSFNRGEC Both sequences were N-terminally fused to a secretion signal peptide sequence of egg white lysozyme for secretion by $P$. pastoris.

\subsection{Construction of Plasmids}

The $\mathrm{H}$ and $\mathrm{L}$ chain genes synthesized were inserted between the AOX 1 promoter and AOX 1 transcriptional terminator in pPICZ A to construct an $\mathrm{H}$ chain and an $\mathrm{L}$ chain expression vector, respectively. The DNA fragment that contained the AOX 1 promoter, L chain gene and AOX 1 transcription terminator, the L chain expression cassette, was cut out from the $\mathrm{L}$ chain expression vector with $B g l$ II and $B a m \mathrm{H}$ I double digestion. The L chain expression cassette was then inserted into the Bam $\mathrm{H}$ I site in the $\mathrm{H}$ chain expression vector to create an expression vector for trastuzumab. In order to improve the insertion of the whole $\mathrm{H}$ chain and $\mathrm{L}$ chain expression cassette into the host genome, a DNA fragment (approximately $450 \mathrm{bp}$ ) covering a 5'-upstream region of the AOX 1 promoter and N-terminal region of the Polyamine oxidase gene was amplified from the host genome by PCR using

5'CCTTTCGTCTTTGGATGTTAGATC3' and 5'CTCACGTTAAGGGATTTTGGTCATGAGATCAgt agtttgcaagtacttataaacaaaattccg3' (where the upper-case letters are the pPICZ A vector sequence and the lowercase letters are the ployamine oxidase gene sequence 349$381 \mathrm{bp}$ from its start codon) as primers, and sub-cloned into the $B g l$ II site, i.e. at the 5'-end of the AOX 1 promoter of the $\mathrm{H}$ chain expression cassette, in the antibody expression plasmid (see Figure 1 for details on the plasmids) using a PCR fragment cloning kit (In-Fusion HD EcoDry Cloning Kit, Takara, Japan).

\subsection{Transformation of $\boldsymbol{P}$. pastoris}

The trastuzumab expression vector was linearized by $\mathrm{Bgl}$ II digestion. $P$. pastoris cells were transformed by electroporation according to the manual provided by Life Technologies. Transformants that appeared on YEPG (1\% yeast extract, $2 \%$ peptone, $1 \mathrm{M}$ sorbitol, $2 \%$ agar and $2 \%$ glucose) plates containing $100 \mathrm{mg} / \mathrm{L}$ Zeocin (Life Technologies) were checked for integrated DNA fragments by PCR using as primers, 


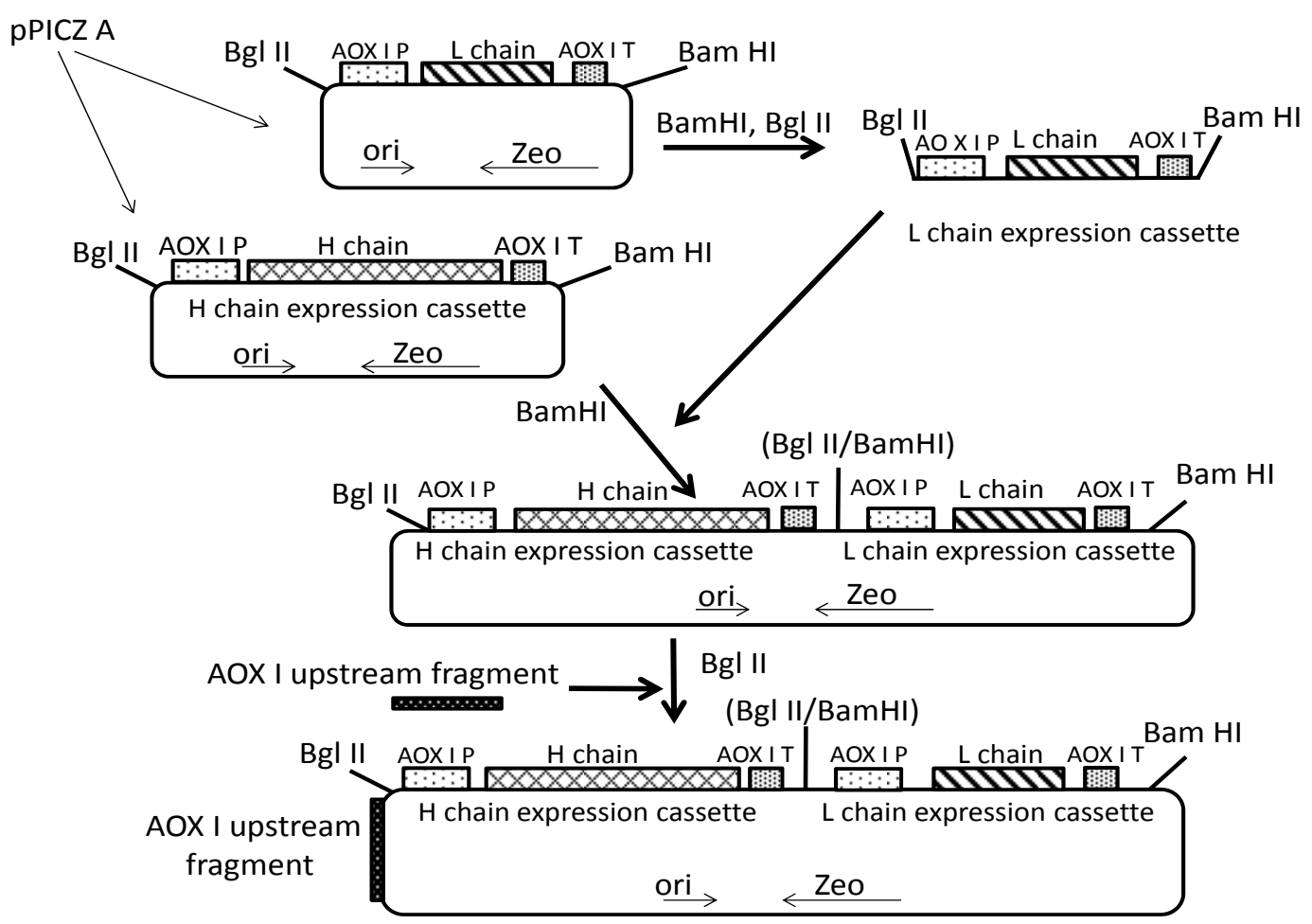

Figure 1. Construction of the expression plasmid for trastuzumab: AOX I P: the Alcohol oxidase 1 promoter region. AOX I T: the Alcohol oxidase 1 transcriptional terminator region. Zeo: Zeocin resistance gene. Ori: plasmid replication origin. AOX I upstream fragment: a DNA fragment amplified by PCR that covers a region upstream of the AOX 1 promoter and a 5' portion of the Polyamine oxidase gene.

\section{5'GACTGGTTCCAATTGACAAGC3' and}

5'GCAAATGGCATTCTGACATCC3', located in the

AOX 1 promoter and AOX 1 transcriptional terminator, respectively.

\subsection{Production of Trastuzumab}

P. pastoris conaining the trastuzumab expression vector was cultured from in $10 \mathrm{~mL}$ of BMGY medium [1\% yeast extract, $2 \%$ peptone, $1.34 \%$ yeast nitrogen base, $100 \mathrm{mM}$ potassium phosphate $(\mathrm{pH} 6.0), 4 \times 10^{-5} \%$ biotin, and $1 \%$ glycerol] overnight at $30^{\circ} \mathrm{C}$ with shaking at 275 rpm. A $100-\mathrm{mL}$ volume of BMGY medium was inoculated with $1 \mathrm{ml}$ of the starting culture. The second culture was incubated for approximately $12 \mathrm{~h}$ at $30^{\circ} \mathrm{C}$ with shaking at $275 \mathrm{rpm}$. Cells were harvested at an $\mathrm{OD}_{600 \mathrm{~mm}}$ of between 1 and 4 and pelleted by centrifugation for 10 $\mathrm{min}$ at $5000 \mathrm{rpm}$ at $4^{\circ} \mathrm{C}$. Induction of protein expression was initiated by resuspending the yeast cells in $100 \mathrm{~mL}$ of BMMY medium [ $1 \%$ yeast extract, $2 \%$ peptone, $1.34 \%$ yeast nitrogen base, $100 \mathrm{mM}$ potassium phosphate (pH 6.0), $4 \times 10^{-5} \%$ biotin, and $1 \%$ methanol]. Incubation was continued at $30^{\circ} \mathrm{C}$ with shaking at $300 \mathrm{rpm}$ for $24 \mathrm{~h}$. A supplemental volume of methanol equal to $1 / 100$ of the culture volume was added at $16 \mathrm{~h}$. Following induction for $24 \mathrm{~h}$, the culture was chilled on ice, and the cells and culture medium were separated by centrifuga- tion for $10 \mathrm{~min}$ at $5000 \mathrm{rpm}$ at $4^{\circ} \mathrm{C}$. The culture medium was stored at $4^{\circ} \mathrm{C}$.

\subsection{Purification of Trastuzumab from Culture Media}

Trastuzumab was recovered from the culture medium with an AKTA explorer 100A (GE Healthcare, NJ) using Streamline rProtein A (GE Healthcare, NJ). The rProtein A resin was equilibrated, and washed with $20 \mathrm{mM}$ Tris$\mathrm{HCl} \mathrm{pH} \mathrm{7.0.} \mathrm{The} \mathrm{culture} \mathrm{supernatant} \mathrm{was} \mathrm{loaded} \mathrm{at} \mathrm{a} \mathrm{ma-}$ ximum capacity of $32 \mathrm{mg} / \mathrm{mL}$ resin at a residence time in excess of 6 min. Trastuzumab was eluted using a $\mathrm{pH}$ gradient from 4.0 to 3.0 in $100 \mathrm{mM}$ sodium citrate. Eluate fractions were adjusted to $\mathrm{pH} 5.0$ with $1 \mathrm{M} \mathrm{Na}_{2} \mathrm{HPO}_{4}$, before being diluted five-fold with $\mathrm{H}_{2} \mathrm{O}$. The $\mathrm{pH}$ was then re-adjusted to 4.5 with $1 \mathrm{M}$ acetic acid before being loaded on a Source 30S (GE Healthcare, NJ) column equilibrated with $25 \mathrm{mM}$ sodium acetate, $\mathrm{pH}$ 4.5. Trastuzumab was eluted using the following stepwise elution protocol: 2 column volumes of Buffer A (12.5 mM sodium acetate, $12.5 \mathrm{mM}$ sodium phosphate, $\mathrm{pH} 6.0$ ), 2 column volumes of $4 \%$ Buffer B (12.5 mM sodium acetate, $12.5 \mathrm{mM}$ sodium phosphate, $0.5 \mathrm{M}$ sodium chloride, pH 6.0), 3 column volumes of $6 \%$ Buffer B, 15 column volumes of $8 \%$ Buffer B, 3 column volumes of $12 \%$ Buffer B, and 2 column volumes of $100 \%$ Buffer B. 


\subsection{N-glycosidase Treatment}

Peptide- $N^{4}$-( $N$-acetyl- $\beta$-glucosaminyl)-asparagine amidase was purchased from Takara (Japan). The samples were treated with the enzyme according to the manufacturer's directions.

\subsection{Elisa}

Assays were conducted essentially as described [12]. Aliquots $(100 \mu \mathrm{l})$ of antigen solution $(3 \mathrm{mg} / \mathrm{mL}$ in PBS) were added to wells of an ELISA plate (COSTAR 9018), and incubated at $4{ }^{\circ} \mathrm{C}$ overnight. The plate was washed 3 times with PBS. The wells were blocked with $1 \%$ BSA in PBS at $37^{\circ} \mathrm{C}$ for $2 \mathrm{hrs}$. The plate was washed 3 times with $0.05 \%$ Tween 20 in PBS. Samples $(100 \mu \mathrm{L})$ were put into the wells, and incubated for $1 \mathrm{hr}$ at room temperature. The plate was again washed 3 times with $0.05 \%$ Tween 20 in PBS. Next, $100 \mu \mathrm{L}$ of $10^{-4}$ diluted anti-human L kappa goat antibody conjugated with HRP (Life Span Biosciences, USA) was put into the wells and incubated for $1 \mathrm{hr}$ at room temperature. The plate was again washed 3 times with $0.05 \%$ Tween 20 in PBS. Detection of bound antibodies was done by measuring absorbance at $450 \mathrm{~nm}$ using 1.2-Phenylenediamine in Citrate buffer containing $\mathrm{H}_{2} \mathrm{O}_{2}$ [13].

\subsection{Surface Plasmon Resonance}

CHO-derived and Pichia-derived trastuzumabs' affinity to Her II was measured with Biacore 3000 (GE Healthcare, NJ, USA). The assay was done in HBST (20 mM Hepes, pH 7.4, $150 \mathrm{mM} \mathrm{NaCl}$ and $0.05 \%$ Tween 20). Her II-Fc chimera (R\&D Systems) was immobilized on a CM5 chip (GE Healthcare, NJ). The antibody was injected at the concentration between $1.56 \mathrm{nM}$ and $50 \mathrm{nM}$. The off rate was calculated by monitoring the assay for at least $2 \mathrm{~min}$. The data obtained were analyzed with global fitting using BIA evaluation soft (GE Healthcare).

\section{RESULTS AND DISCUSSION}

\subsection{Construction of Expression Plasmids for Trastuzumab}

A plasmid containing the antibody heavy chain and light chain secretory expression units under the control of the AOX 1 promoter was constructed (Figure 1). To increase the efficiency of integration of the vector into the host AOX 1 promoter region by homologous recombination, digestion at a unique site in the AOX 1 promoter region to linearize the original vector is recommended by the manufacturer. However, since the antibody expression plasmid contained two AOX 1 promoters, linearization of the expression vector with a restriction enzyme that cuts inside the AOX 1 promoter would separate the $\mathrm{H}$ chain and the light chain expression cassettes. A DNA fragment of the upstream region of the AOX 1 gene promoter and a part of the flanking gene, Polyamine oxidase, was amplified from the genome by PCR, and then put into the $B g l$ II site, i.e. at the 5'-end of the AOX 1 promoter of the $\mathrm{H}$ chain expression cassette. Linearization of the plasmid with $B g l$ II digestion would be expected to facilitate integration of the entire antibody expression construct through homologous recombination between the host genome and the plasmid in the region surrounding the $B g l$ II site.

\subsection{Isolation of Transformants, and Checking of the Antibody Expression Construct}

Using the transformation conditions recommended by the manufacturer, only three colonies appeared on plates containing Zeocin $(100 \mathrm{mg} / \mathrm{mL})$, despite that the original vector, pPICZ A, could transform hundreds of colonies under the same conditions. It is thought that the expression of the antibody might be harmful to the cells. Genomic DNA of these three colonies was isolated, and checked for the insertion of the expression construct by PCR. Two of them showed integration of the construct. One was selected for further cultivation and production.

\subsection{Secretion of Trastuzumab, and Its Characterization}

After cultivation and induction of the transformant selected, the culture medium was separated from the cells by centrifugation. The production of the antibody in the culture medium was checked by western blotting using anti-human IgG Fc and anti-human $\kappa$ (Figure 2 (a)). The heavy chain produced by $P$. pastoris was detected as two bands. The main was at a slightly higher molecular weight position than the one produced by $\mathrm{CHO}$, but the weaker band was seen at the same position. The light chain was detected as one band almost at the same position as that produced by $\mathrm{CHO}$. The antibody in the culture medium was then affinity-purified with a Protein A column, and the product was analyzed by SDS-PAGE under reduced and non-reduced conditions. Under nonreduced conditions, the molecular weight of the antibody was approximately $250 \mathrm{kDa}$, and almost the same as that produced by $\mathrm{CHO}$ (Figure 2 (b)). The antibody is considered to be correctly assembled to form a heterotetramer. The light chain and heavy chain bands were separated by SDS-PAGE, and transferred to a membrane filter to analyze their $\mathrm{N}$-terminal amino acid sequences with a sequencer. The $\mathrm{N}$-terminal sequences of the heavy chain and light chain were revealed to be EVQLV- and DIQMT-, respectively. These results were consistent with the amino acid sequences predicted from the DNA. The chicken lysozyme signal peptide of both chains was precisely processed in $P$. pasotris. 


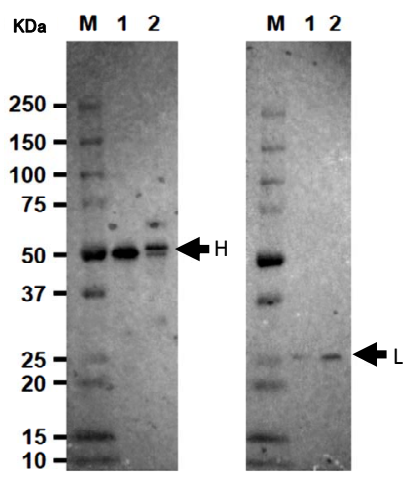

(a)

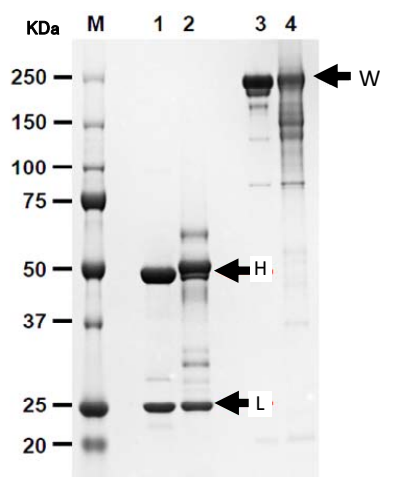

(b)
Figure 2. Western blotting and SDS-PAGE of trastuzumab secreted in the Pichia pastoris culture medium. (a) Left panel; western blotting with anti-human IgG Fc. H indicates the antibody's heavy chain. Right panel; western blotting with anti-human light chain kappa. L indicates the antibody's light chain. Lane M; molecular weight markers. Lane 1; trastuzumab produced by $\mathrm{CHO}$. Lane 2 ; trastuzumab produced by $P$. pastoris; (b) Lanes 1 and 2; A Coomassiee blue-stained SDSPAGE gel under reduced conditions. Lanes 3 and 4; A Coomassie blue-stained SDS-PAGE gel under non-reduced conditions. $\mathrm{H}, \mathrm{L}$ and $\mathrm{W}$ indicate the $\mathrm{H}$ chain, $\mathrm{L}$ chain and hetero-tetramer, respectively. Lane M; molecular weight markers. Lanes 1 and 3; trastuzumab produced by CHO. Lanes 2 and 4; rProtein A-captured trastuzumab produced by Pichia pastoris.

\subsection{Analysis of Sugar Chains}

The antibody was further purified with an ion exchange column, Resource S (GE Healthcare Japan), and treated with Peptide- $N^{4}$-( $N$-acetyl- $\beta$-glucosaminyl)-asparagine amidase. The samples were analyzed by SDS-PAGE (Figure 3). After treatment with the enzyme, the heavy chain showed a decrease in molecular weight and the same mobility as the one produced by CHO (Figure 3). From this result, the heavy chain produced by $P$. pastoris has major sugar chains linked to asparagine as is the case with that produced by $\mathrm{CHO}$. The sugar chains removed from the heavy chain produced by $P$. pastris were further analyzed with MALDI-TOF mass spectroscopy. Figure 4 shows the mass spectra. From the peaks in the spectra, the sugar chain structures were estimated to be $\mathrm{Man}_{9-}$ GlcNAc $_{2}$ (Mw: 1962), Man $_{10}-G_{\text {GlcNAc }}$ (Mw: 2124), $\mathrm{Man}_{11}-\mathrm{GlcNAc}_{2}$ (Mw: 2286) and $\mathrm{Man}_{12}-\mathrm{GlcNAc}_{2}(\mathrm{Mw}$ : 2448). They were all high-mannose type sugars, however, there were no hyper mannosylated or fucosylated sugar chains detected. Hyper-mannosylated sugar chains are typical of yeast proteins, and thought to be immunogenic for human [14-16]. However, high-mannose type sugar chains are frequently observed in human sugar chains. Fucosylation of the sugar chains of antibodies, usually observed in the $\mathrm{CHO}$ product, was reported to have an, adverse effect on effector functions $[17,18]$. The antibody produced by $P$. pastoris could be expected to have higher ADCC (antibody-dependent cell mediated cytotoxicity) than the one produced by $\mathrm{CHO}$.

\subsection{Affinity for Human Her II}

Binding to Her II was compared between the antibody produced by $P$. pastris and that produced by $\mathrm{CHO}$ using ELISA and Surface Plasmon Resonance. The affinity curves and constants were almost the same (Figure 5 and

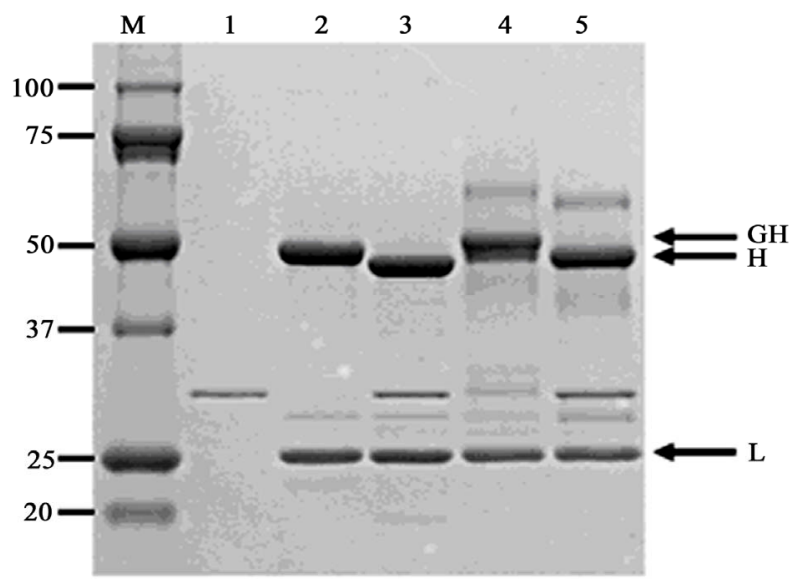

Figure 3. Trastuzumab treated with Peptide- $N^{4}-(N$-acetyl- $\beta$ glucosaminyl)-asparagine amidase. Samples were analyzed by SDS-PAGE under reduced conditions. Lane $\mathrm{M}$; molecular weight markers $(\mathrm{kDa})$. Lane 1 ; Peptide- $N^{4}$ - $(N$-acetyl- $\beta$ - glucosaminyl)-asparagine amidase. Lanes 2 and 3; trastuzumab produced by CHO. Lanes 4 and 5; trastuzumab produced by $P$. pastoris. Lanes 2 and 4; trastuzumab without Peptide- $N^{4}$ - $(N$-acetyl- $\beta$-glucosaminyl)-asparagine amidase treatment. Lanes 3 and 5 ; trastuzumab with Peptide- $N^{4}$ - $(N$-acetyl- $\beta$ - glucosaminyl)-asparagine amidase treatment. $\mathrm{L}$ indicates the $\mathrm{L}$ chain. $\mathrm{H}$ indicates the $\mathrm{H}$ chain without $\mathrm{N}$-linked glycans and $\mathrm{GH}$ indicates the $\mathrm{H}$ chain with N-linked glycans. The gel was stained with Coomassiee blue.

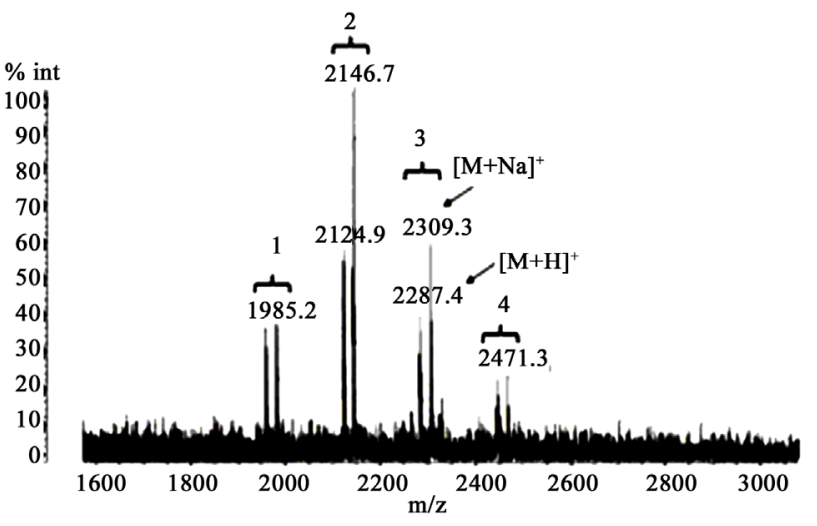

Figure 4. MALDI-TOF mass spectra of N-linked glycans attached to trastuzumab produced by $P$. pastoris. Each N-glycan has two peaks, one with an $\mathrm{H}$ ion and another with an $\mathrm{Na}$ ion. Structures deduced from peaks 1, 2, 3 and 4 are $\mathrm{Man}_{9} \mathrm{GlcNAc}_{2}$ (Mw: 1962), $\operatorname{Man}_{10} \mathrm{GlcNAc}_{2}$ (Mw: 2124), $\operatorname{Man}_{11} \mathrm{GlcNAc}_{2}$ (Mw: 2286) and $\mathrm{Man}_{12} \mathrm{GlcNAc}_{2}$ (Mw: 2448), respectively. 


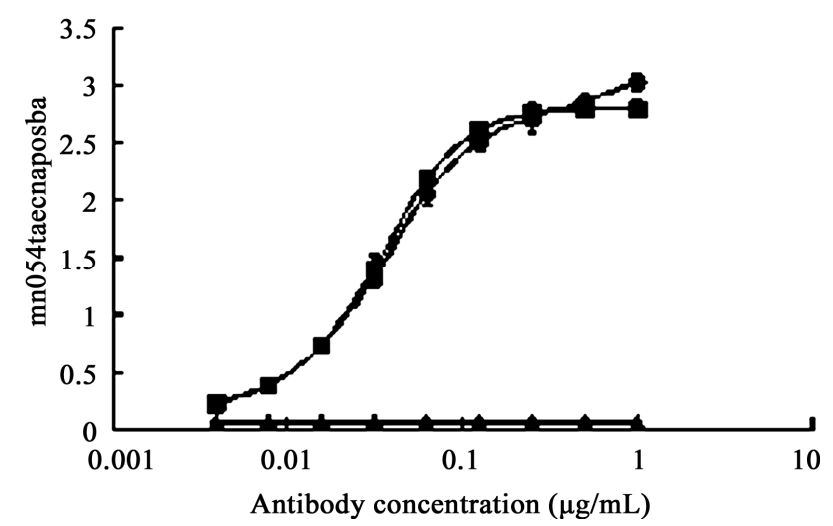

Figure 5. Comparison of reactivity to the antigen with the $\mathrm{CHO}$ product. Assays were carried out with ELISA as described in materials and methods. $\boldsymbol{\Delta}$ : Rituximab (an antibody to CD20, a negative control). $\bullet$ : trastuzumab produced by CHO. $\mathbf{~}$ : trastuzumab produced by $P$. pastris.

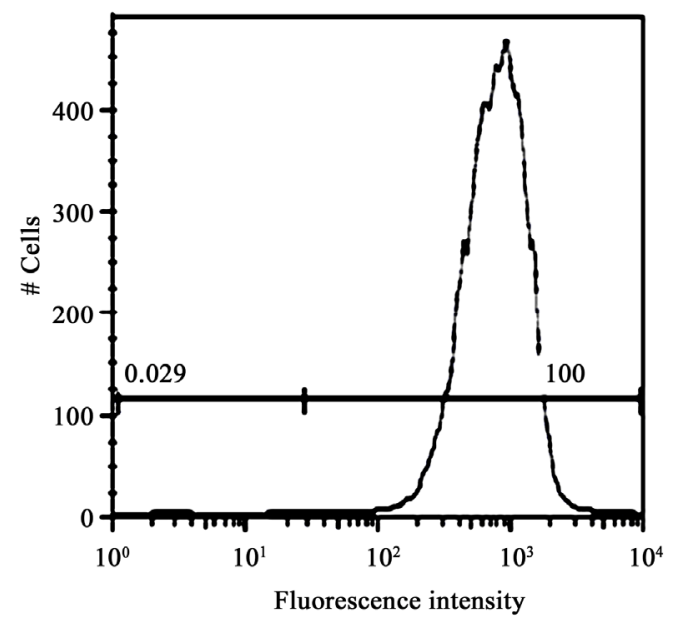

(a)
Table 1). Reactivity to the breast cancer cell line SK-R-3 overexpressing Her II was also compared using flow cytometry (Figure 6). The reaction pattern was very similar, whereas rituximab did not show any bindings to the cell line.

\section{CONCLUSIONS}

An N-terminal processed and folded trastuzumab hetero-

Table 1. Kinetic parameters of trastuzumab produced by $\mathrm{CHO}$ and Pichia pastoris.

\begin{tabular}{ccccc}
\hline Trastuzumab by & $\mathbf{K}_{\mathbf{a}}\left(\mathbf{M}^{-1} \mathbf{s}^{-\mathbf{1}}\right)$ & $\mathbf{K}_{\mathbf{d}}\left(\mathbf{s}^{-\mathbf{1}}\right)$ & $\mathbf{K}_{\mathbf{A}}\left(\mathbf{M}^{-1}\right)$ & $\mathbf{K}_{\mathbf{D}}(\mathbf{n M})$ \\
\hline CHO & $4.25 \times 10^{5}$ & $5.21 \times 10^{-5}$ & $8.17 \times 10^{9}$ & 0.12 \\
P. pastoris & $4.26 \times 10^{5}$ & $8.72 \times 10^{-5}$ & $5.33 \times 10^{9}$ & 0.19 \\
\hline
\end{tabular}

$\mathrm{k}_{\mathrm{a}}$ and $\mathrm{k}_{\mathrm{d}}$ values were calculated by SPR analyses (see the text); $\mathrm{K}_{\mathrm{A}}$ and $\mathrm{K}_{\mathrm{D}}$ values were based on $\mathrm{k}_{\mathrm{a}}$ and $\mathrm{k}_{\mathrm{d}}$.

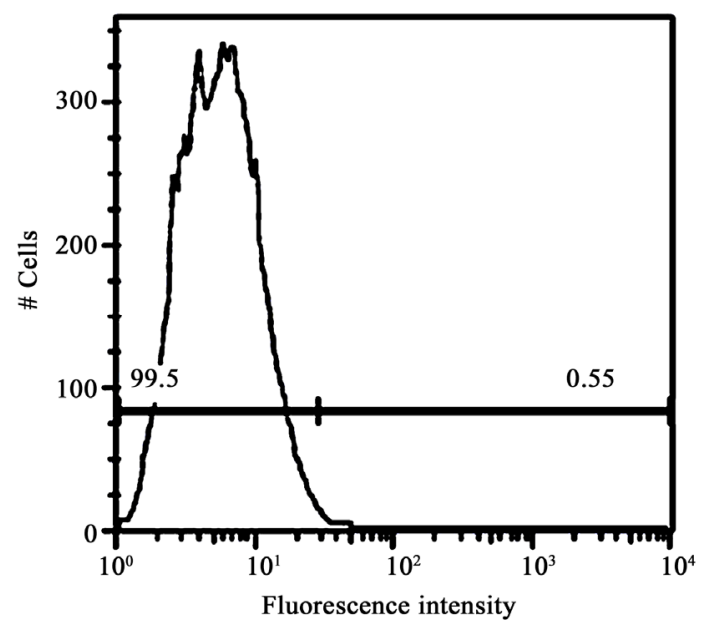

(b)

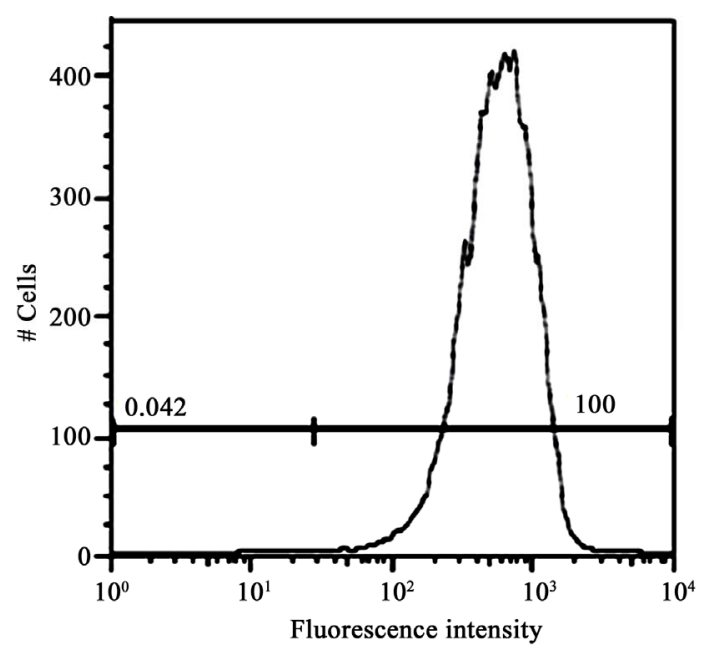

(c)

Figure 6. Reactivity to the Her II-overexpressing breast cancer cell line SK-BR-3 analyzed by flow cytometry. (a) trastuzumab produced by CHO. (b) trastuzumab produced by P. pastoris. (c) rituximab. Reactivity to the cells was detected with a flow cytometer using an Alexa 488-conjugated anti-human IgG Fc antibody as a secondary antibody. Numbers in the figures indicate the percentage of cells in peaks. 
tetramer was highly expressed at $10 \mathrm{mg} / \mathrm{L}$ in flask cultures by Pichia pastoris transformed with an expression plasmid. The trastuzumab produced by $P$. pastoris showed similar HER2-binding activity to that produced by $\mathrm{CHO}$, and had N-linked sugar chains. Glycan structures predicted from MALDI/TOF mass spectra were $\mathrm{Man}_{9} \mathrm{GlcNAc}_{2}$, $\mathrm{Man}_{10} \mathrm{GlcNAc}_{2}, \mathrm{Man}_{11} \mathrm{GlcNAc}_{2}$ and $\mathrm{Man}_{12} \mathrm{GlcNAc}_{2}$, but no fucosylated or hyper-mannosylated glycans were observed. Reactivity to the antigen, Her II, was almost the same for that produced by $\mathrm{CHO}$. Antibody production using Picha pastoris could be an effective substitute for the expensive systems using mammalian cells.

\section{REFERENCES}

[1] Kito, M., et al. (2002) Construction of engineered CHO strains for high-level production of re-combinant proteins. Applied Microbiological Biotechnology, 60, 442-448. doi:10.1007/s00253-002-1134-1

[2] Barnes, L.M., Bentley, C.M. and Dickson, A.J. (2000) Advances in animal cell recombinant protein production: GS-NS0 expression system. Cy-totechnology, 32, 109123. doi:10.1023/A:1008170710003

[3] Farid, S.S. (2006) Established bioprocesses for producing antibodies as a basis for future planning. Advances in Biochemical Engineering/Biotechnology, 101, 1-42. doi:10.1007/10 014

[4] Cregg, J.M., et al. (2000) Recombinant protein expression in Pichia pastoris. Molecular Biotechnology, 16, 2352. doi:10.1385/MB:16:1:23

[5] Romanos, M.A., Scorer, C.A. and Clare, J.J. (1992) Foreign gene expression in yeast: A review. Yeast, 8, 423488. doi: $10.1002 /$ yea.320080602

[6] Cregg, J.M., et al. (1985) Pichia pastoris as a host system for transformations. Molecular Cell Biology, 5, 33763385.

[7] Grinna, L.S. and Tschopp, J.F. (1989) Size distribution and general structural features of N-linked oli-gosaccharides from the methylotrophic yeast, Pichia pastoris. Yeast, 5, 107-115. doi:10.1002/yea.320050206

[8] Goodrick, J.C., et al. (2001) High-level expression and stabilization of recombinant human chitinase produced in a continuous constitutive Pichia pastoris expression system. Biotechnology and Bioengineering, 74, 492-497. doi:10.1002/bit.1140
[9] Schilling, B.M., Goodrick, J.C. and Wan, N.C. (2001) Scale-up of a high cell density continuous culture with Pichia pastoris X-33 for the constitutive expression of rhchitinase. Biotechnology Progress, 17, 629-633. doi:10.1021/bp010041e

[10] Hellwig, S., et al. (2001) Analysis of single-chain antibody production in Pichia pastoris using on-line methanol control in fed-batch and mixed-feed fermentations. Biotechnology and bioengineering, 74, 344-352. doi:10.1002/bit.1125

[11] Carter, P., et al. (1992) Humanization of an anti-p185HER2 antibody for human cancer therapy. Proceedings of $\mathrm{Na}$ tional Academy Science of the USA, 89, 4285-4289. doi:10.1073/pnas.89.10.4285

[12] Shibui, T. and Nagahari, K. (1992) Secretion of a functional Fab fragment in Escherichia coli and the influence of culture conditions. Applied Microbiological Biotechnology, 37, 352-357. doi:10.1007/BF00210991

[13] Cabilly, S. (1989) Growth at sub-optimal temperatures allows the production of functional, anti-gen-binding $\mathrm{Fab}$ fragments in Escherichia coli. Gene, 85, 553-557. doi:10.1016/0378-1119(89)90451-4

[14] Dean, N. (1999) Asparagine-linked glycosylation in the yeast Golgi. Biochimica et Biophysica Acta, 1426, 309. 322. doi:10.1016/S0304-4165(98)00132-9

[15] Ballou, C.E. (1990) Isolation, characterization, and properties of Saccharomyces cerevisiae mnn mutants with nonconditional protein glycosylation defects. Methods Enzymology, 185, 440-470. doi:10.1016/0076-6879(90)85038-P

[16] Yip, C.L., et al. (1994) Cloning and analysis of the Saccharomyces cerevisiae MNN9 and MNN1 genes required for complex glycosylation of secreted proteins. Proceedings of National Academy Science of the USA, 91, 27232727. doi:10.1073/pnas.91.7.2723

[17] Niwa, R., et al. (2004) Defucosylated chimeric anti-CC chemokine receptor 4 IgG1 with enhanced antibody-dependent cellular cytotoxicity shows potent therapeutic activity to T-cell leukemia and lymphoma. Cancer Research, 64, 2127-2133. doi:10.1158/0008-5472.CAN-03-2068

[18] Yamane-Ohnuki, N., et al. (2004) Establishment of FUT8 knockout Chinese hamster ovary cells: An ideal host cell line for producing completely defucosylated antibodies with enhanced anti-body-dependent cellular cytotoxicity. Biotechnology and bioengineering, 87, 614-622. doi:10.1002/bit.20151 